\title{
Recent XAS studies into Homogeneous metal catalyst in fine chemical and pharmaceutical syntheses
}

\author{
Grant J Sherborne and Bao N Nguyen*
}

\begin{abstract}
A brief review of studies using X-ray Absorption Spectroscopy (XAS) to investigate homogeneous catalytic reactions in fine chemical and pharmaceutical context since 2010 is presented. The advantages of the techniques over traditional lab-based analytical tools, particularly when NMR spectroscopy fails to deliver mechanistic insights, are summarised using these examples. A discussion on the current limitations of the techniques and challenges in the near future is also included.
\end{abstract}

Keywords: X-ray absorption spectroscopy, Homogeneous catalysis, Mechanism

XAS has been very successfully applied as a technique to study heterogeneous catalysts $[1,2]$. Electronic and structural information can be extracted from the absorption edge region (X-ray Absorption Near Edge Spectroscopy or XANES) and the scattering pattern (Extended X-ray Absorption Fine Structure Spectroscopy or EXAFS), respectively (Fig. 1) [3]. The major advantage of the technique, in a catalysis context, is that the metal centre of the catalyst can be selectively observed under turnover conditions while ignoring organic species in the system.

Applications of XAS to homogeneous catalysis in liquid phase, however, are limited. This is due firstly to the inherently poor signal-to-noise ratio, a result of low concentration of catalyst and background absorption by organic materials. Another, less obvious, obstacle is the required effort in developing a suitable sample environment for each study, which can improve signal quality. This requires good understanding of the physics of the technique, and an additional level of commitment to planning and testing of sample environment for synthetic researchers. Studies at low energy $(<9 \mathrm{keV}$, e.g. $\mathrm{Cu}$, $\mathrm{Fe}, \mathrm{Ni}, \mathrm{Co}$ ) are particularly difficult in solution as the

\footnotetext{
* Correspondence: b.nguyen@leeds.ac.uk

Institute of Process Research \& Development, School of Chemistry, University of Leeds, Woodhouse Lane, Leeds LS2 9JT, UK
}

solvent can significantly absorb radiation. Consequently, sample environments vary from stopped-flow cuvettes [4] to PTFE [5, 6] and PEEK cells [7] with Kapton ${ }^{\circ}$ windows. In addition, time resolved in situ studies sometimes suffer from sample decomposition by radiation, which necessitates spectroscopic flow-cells through which reaction mixtures can be pumped continuously. These flow-cells also enable steady state measurements and time resolution through changes to residence time and flow-rate $[8,9]$. When such problems are overcome, XAS has been demonstrated to be a highly effective method, and in some cases the only appropriate method, to answer many mechanistic questions in homogeneous catalysis.

In this mini-review, we highlighted recent successful XAS studies of homogeneous catalysts since 2010. As we aim to encourage interest from the synthetic community, only discrete molecular catalysts and nanopaticles, which catalyse organic transformations in fine chemical/pharmaceutical context, will be included. Studies using static samples will be discussed first, before the more technologically challenging in situ studies under turnover conditions. Readers who seek more detailed information on the techniques and its practical aspects should refer to comprehensive reviews of the fields by Eisenberger [10], Evans [11], and Lamberti [3]. 


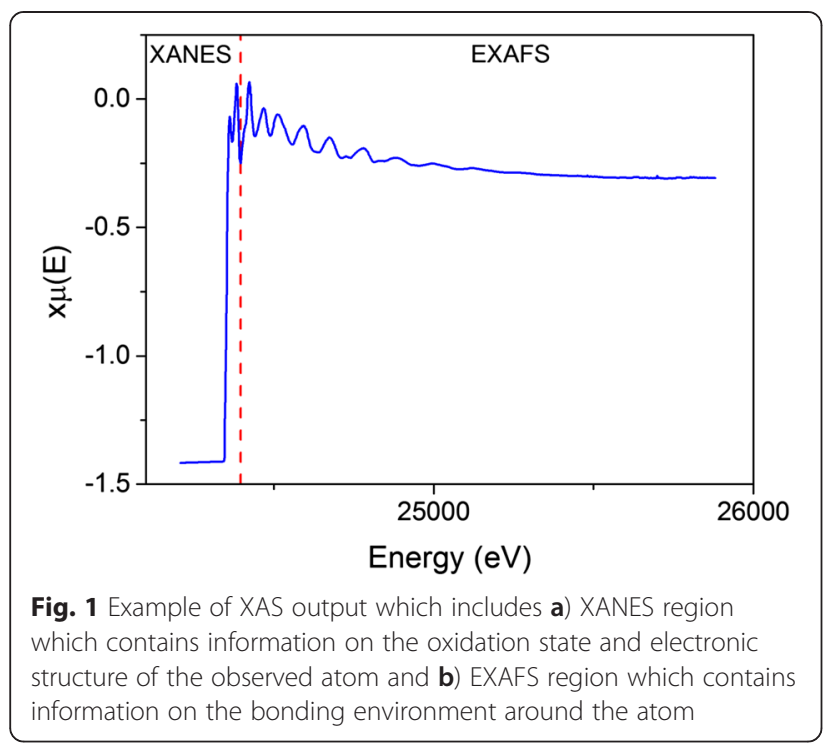

A simple and effective study into the role of chiral phosphate counterions in gold-catalysed reaction was reported by Nguyen et al. [12]. In their study, Au L-edge EXAFS spectrum of $\left[\mathrm{Ph}_{3} \mathrm{PAu}\right][\mathrm{OP}(=\mathrm{O})-\mathrm{BINOL}]$ (1) in toluene clearly indicated a short $\mathrm{Au}-\mathrm{OP}(=\mathrm{O})-\mathrm{BINOL}$ bond $(2.02 \AA)$ at resting state in solution (Fig. 2). This suggests that the chiral phosphate counterion can act as a chiral ligand in many enantioselective gold-catalysed reactions [13-15].

The oxidation state of gold catalyst in an Au-catalysed cyclobenzannulation reaction, a common debate in homogenous gold catalysis [16], was also studied by Nguyen (Scheme 1) [12]. Monitoring stoichiometric steps of the catalytic cycle using XANES indicated that the majority of Au-species are $\mathrm{Au}(\mathrm{III})$, based on the absorption edge position which is oxidation state sensitive, and a stoichiometry different from 1: 1 between $\mathrm{AuCl}_{3}$ and the substrate. This led to the detection and characterisation by ${ }^{1} \mathrm{H}$ NMR and HRMS of novel intermediates four and five, which reacts with phenylacetylene to give the final product.

Hashmi and Bertagnolli also employed XAS to investigate the oxidation state of the gold catalyst in an $\mathrm{Au}$ catalysed oxidative esterification [6]. No $\mathrm{Au}-\mathrm{Au}$ bond was detected by Au L-edge EXAFS, supporting the homogeneous nature of the catalyst. The oxidation state of gold species in these samples was determined through Linear Combination Analysis (LCA) of XANES spectra against those of $\mathrm{HAuCl}_{4} / \mathrm{MeCN}$ and $\mathrm{AuCl}$ as standards. The results indicated a $\mathrm{Au}(\mathrm{III}): \mathrm{Au}(\mathrm{I})$ ratio of $88: 12$ at the beginning of the reaction, which changed to $14: 86$ after $24 \mathrm{~h}$ when the oxidant is consumed (Scheme 2).

Fe-catalysed cross-coupling reactions are a rapidly growing field of research in which mechanistic insights are difficult to obtain due to the paramagnetic nature of many Fe-species which precludes NMR techniques. Bauer and co-workers reported the use of XAS to study the mechanism of reaction between aryl halides and Grignard reagents (Scheme 3) [17]. Titration of the precatalyst $\mathrm{Fe}(\mathrm{acac})_{3}$ with $\mathrm{PhMgCl}$ (10) was monitored using Fe K-edge XANES spectra, which led to assignment of a $\mathrm{Fe}(\mathrm{I})$ active species. However, EXAFS data suggested the formation of nanoparticles (13 \pm 2 atoms),

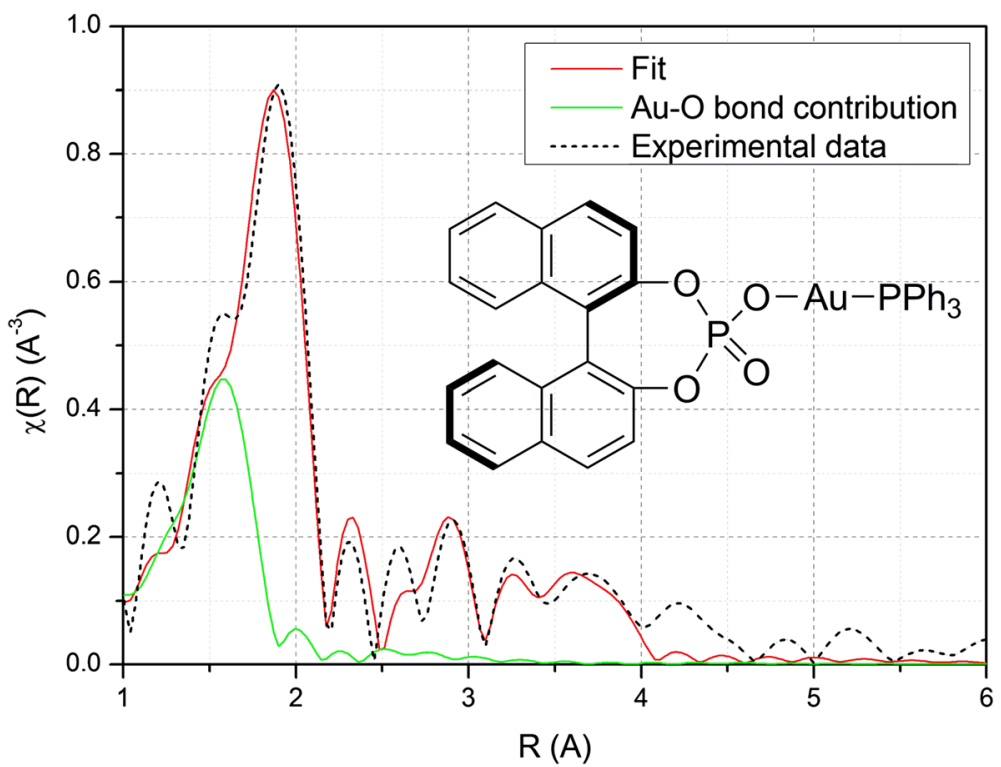

Fig. 2 EXAFS spectrum and fitting for $\left[\mathrm{Ph}{ }_{3} \mathrm{PAu}\right][\mathrm{OP}(=\mathrm{O})-\mathrm{BINOL}]$ (1) (reproduced with permission from ACS Publications) 


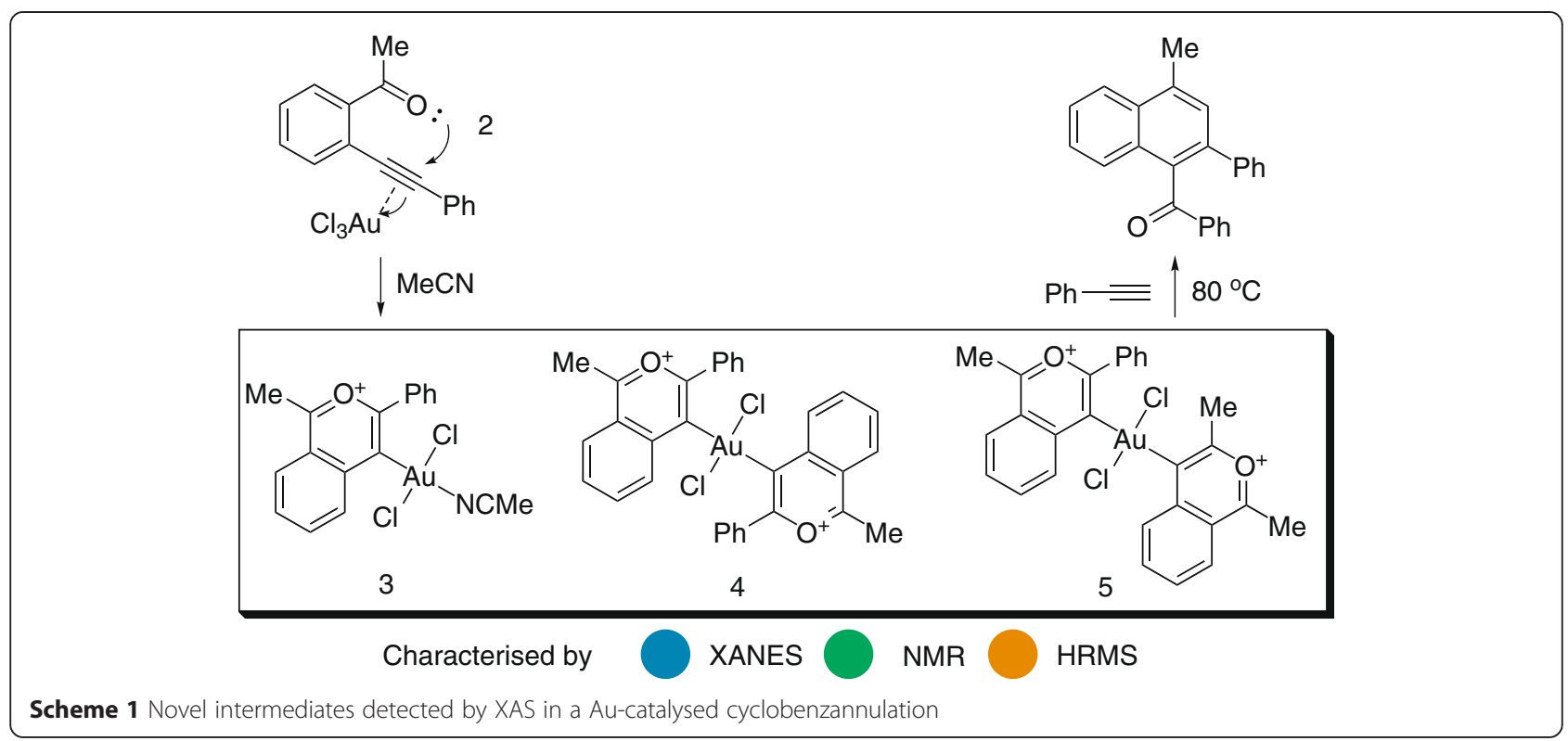

i.e. Fe-Fe bonds, on which the Fe(I) centres on the surface can undergo oxidative addition with aryl halides to become $\mathrm{Fe}(\mathrm{III})$ centres. The average observed oxidation state of $\mathrm{Fe}$ was determined to be +1.7 under reaction conditions based on the position of the absorption edge.

The above study also demonstrated that the boundary between homogeneous and heterogeneous catalysis can sometime be blurred in transition metal catalysed reactions $[18,19]$. Another investigation by Fairlamb and Lee on a Suzuki-Miyaura reaction catalysed by Pdnanoparticles differentiated between catalysis on the surface of Pd-nanoparticles and catalysis by leached Pd atoms/colloids in solution [20]. Ex situ and in situ measurements at the Pd-K edge were used to link catalytic activity to defect sites on the $1.8 \mathrm{~nm}$ Pd nanoparticles, comprised of $236 \mathrm{Pd}$ atoms, which was supported by kinetics, TEM and $\mathrm{Hg}$ poisoning experiments. This is the first incontrovertible evidence that this type of reaction can operate under heterogeneous conditions.

The Chan-Lam reaction, a popular C-N coupling reaction under very mild conditions, was investigated by Tromp et al. using time-resolved in situ XAS and UV/ Vis spectroscopy [4]. The use of energy dispersive, rather than energy scanning, XAS allowed collection of XANES and EXAFS spectra in seconds/min timescale. Stable intermediates of the catalytic cycle were characterised, using a combination of XANES, EXAFS and UV/Vis spectroscopy, in step-wise fashion using $\left[\mathrm{Cu}\left(\mu_{2}-\mathrm{OH}\right)(\mathrm{T}\right.$ MEDA) $]_{2} \mathrm{Cl}_{2}$ (12) as catalyst (Scheme 4). Simultaneous injection of all reaction components in stoichiometric amounts led to formation of a monomeric $\mathrm{Cu}(\mathrm{I})$ active catalytic species. As the product $N$-phenylimidazole (13)<smiles>CCCCOC(=O)c1ccccc1</smiles>

Linear Combination Analysis of XANES spectra

During reaction $(1 \mathrm{~h})$ After reaction $(24 \mathrm{~h})$

$\begin{array}{cc}\mathrm{HAuCl}_{4} / \mathrm{MeCN} & \mathrm{AuCl} \\ 88 \% & 12 \% \\ 14 \% & 86 \%\end{array}$

XANES 


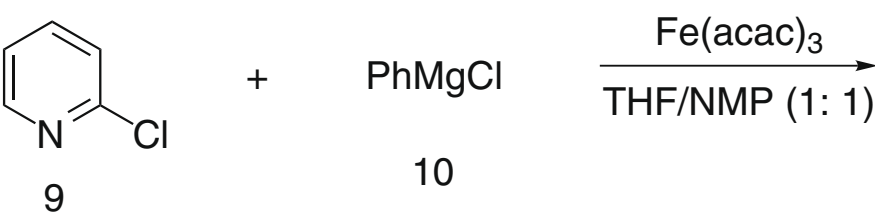<smiles>c1ccc(-c2ccccn2)cc1</smiles>

11

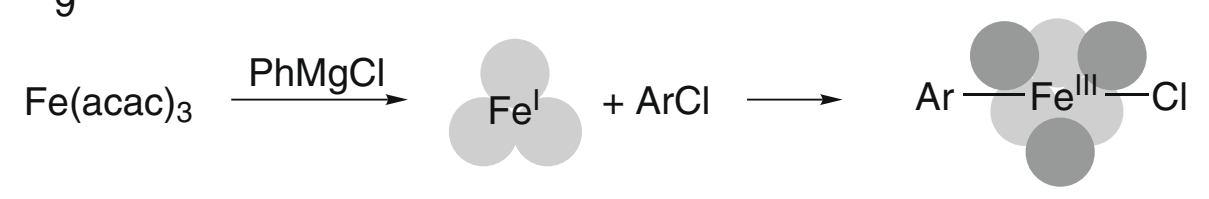

\section{Characterised by}

XANES

EXAFS

UV/Vis

Scheme 3 Fe-catalysed coupling reaction between aryl halides and Grignard reagents and its mechanism

is formed, the $\mathrm{Cu}(\mathrm{II})$ pre-catalyst was restored. The proposed short-lived $\mathrm{Cu}(\mathrm{III})$ intermediate 15 of this reaction, however, could not be observed.

Lei et al. studied a less well-known but synthetically useful $\mathrm{Cu}$-catalysed $\mathrm{C}$ - $\mathrm{C}$ coupling reaction between acetylacetone and an aryl halide, using a combination of in situ FTIR and $\mathrm{Cu}$ K-edge XAS [7]. Acetylacetone was found to act both as a ligand for the $\mathrm{Cu}$-catalyst and a coupling partner. Importantly, in situ Cu K-edge XANES and EXAFS studies of a stoichiometric reaction between $\mathrm{K}(\mathrm{acac})$ and $\mathrm{CuI}$ (Scheme 5) led to identification of product $\left[\mathrm{Cu}(\mathrm{I})(\mathrm{acac})_{2}\right]^{-} 18$, which disproportionates to $\left[\mathrm{Cu}(\mathrm{II})(\mathrm{acac})_{2}\right] 19$, confirmed by FT-IR, and $\mathrm{Cu}(0)$ within $10 \mathrm{~min}$ in a catalyst deactivation pathway.
Tanaka and Shishido recently reported an in situ timeresolved Ni K-edge XAS study of a reaction between [Ni(bipy)(COD)] and $\mathrm{PhBr}$ giving 1,1'-biphenyl as product within an impressive timescale of $100 \mathrm{~s}$ [21]. The starting complex [Ni(bipy)(COD)], the oxidative addition product $\left[\mathrm{Ni}(\right.$ bipy $\left.)(\mathrm{Ph})(\mathrm{Br})(\mathrm{DMF})_{2}\right]$, and the by-product $[\mathrm{Ni}(\mathrm{bi}-$ py) $\mathrm{Br}_{2}(\mathrm{DMF})_{2}$ ] were assigned and characterised by EXAFS fitting. A Ni-Br bond length of $2.61 \AA$ and a Ni$\mathrm{Ph}$ bond length of $2.08 \AA$ were determined for [Ni(bipy) $\left.(\mathrm{Ph})(\mathrm{Br})(\mathrm{DMF})_{2}\right]$. The Ni-Br bond length was shortened to $2.47 \AA$ in the by-product [ $\mathrm{Ni}($ bipy $\left.) \mathrm{Br}_{2}(\mathrm{DMF})_{2}\right]$ after formation of 1,1'-biphenyl. The concentrations of these three major species were extracted by LCA of both XANES and EXAFS spectra of the reaction over time, leading to near

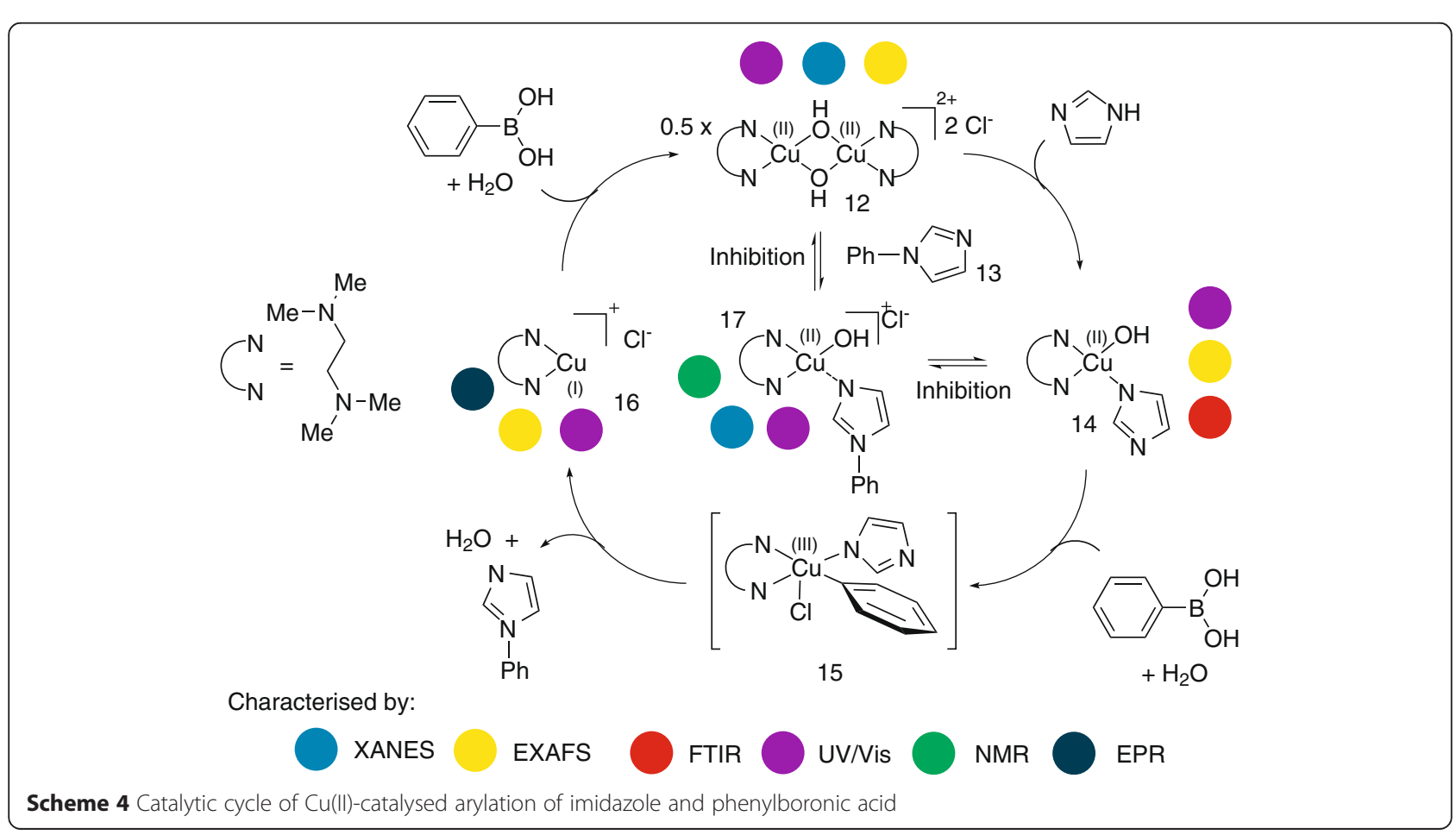




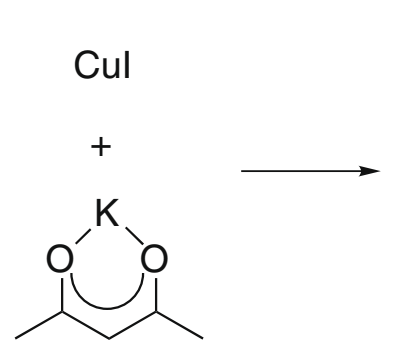

Component 1

Characterised by<smiles></smiles>

18

Component 2

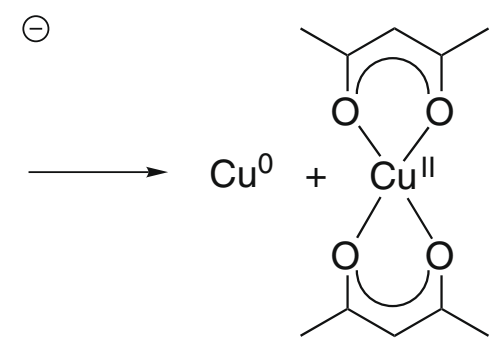

19

Component 3

XANES

EXAFS

FTIR

Scheme 5 Kinetic profile of the stoichiometric reaction between K(acac) and Cul, and the corresponding catalyst deactivation pathway. (partially reproduced with permission from ACS Publications)

identical reaction profiles (Fig. 3). Observed coordination of DMF molecules to Ni explains experimental observation that polar solvents are beneficial in the reaction.

Recent advances in XAS include the applications of HERFD-XAS (High-Energy Resolution Fluorescence Detected XAS), [22-24] and RIXS (Resonant Inelastic X-ray Scattering), $[25,26]$ which give much higher resolution for the edge and pre-edge region. Bauer took advantage of these to improve his prior study of Fe-catalysed Michael addition of a $\beta$-diketone to an enone [27]. Higher resolution Fe K-edge XANES data led to a corrected ratio of $\left[\mathrm{FeCl}_{4}\right]^{-}:\left[\mathrm{Fe}(\mathrm{L})_{2}\left(\mathrm{H}_{2} \mathrm{O}\right)_{2}\right]^{+}$of $78.6: 21.4$, instead of $50: 50$ as previously determined using standard XANES [28]. A titration experiment at $\mathrm{Fe} \mathrm{K}$-edge with $\mathrm{Et}_{3} \mathrm{NBzCl}$ revealed that $\mathrm{Cl}^{-}$poisons the catalyst by converting it to the inactive $\left[\mathrm{FeCl}_{4}\right]^{-}$. This explains the lower catalytic activity observed when $\mathrm{FeCl}_{3}$ was used as pre-catalyst instead of $\mathrm{Fe}\left(\mathrm{ClO}_{4}\right)_{3}$.

\section{Conclusions}

Applications of XAS to homogeneous catalysis in synthetic context are surprisingly few, given its potential insights on the oxidation state, electronic configuration and coordination environment of the catalyst under turnover conditions. However, a number of studies in recent years have overcome its technical hurdles to demonstrate its power over a wide range of transition metal catalysed reactions. Whilst characterisation of intermediates using XAS alone is difficult, this can often be solved by complementary use of more traditional analytical tools such as UV/Vis, IR, NMR spectroscopy and mass spectrometry.

Practical problems such as very fast reactions, sample decomposition and reaction acceleration due to local heating effect [29], persists. A number of technological solutions for these problems have been developed. These include stopped-flow freeze-quenching to prolong the life-time of intermediates [30], and multiple-windows flow-reactors which enable steady-state observation of a reaction at different reaction time by controlling the flowrate [8]. Many XAS studies on more challenging homogeneous catalytic reactions can therefore be expected in the near future.
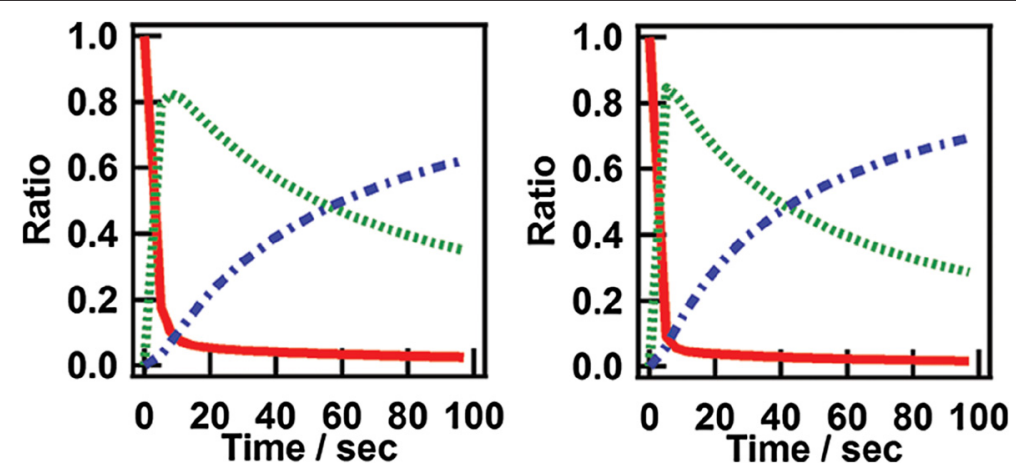

Fig. 3 Time course of the concentration of each LCA extracted species (left: XANES; right: EXAFS); red solid line: [Ni(bipy)(COD)]; green dotted line: $\left[\mathrm{Ni}(\mathrm{bipy})(\mathrm{Ph})(\mathrm{Br})(\mathrm{DMF})_{2}\right]$; blue hashed line: $\left[\mathrm{Ni}\left(\mathrm{bipy}_{\mathrm{B}} \mathrm{Br}_{2}(\mathrm{DMF})_{2}\right]\right.$. (reproduced with permission from ACS Publications) 


\section{Abbreviations}

Acac: Acetylacetate; bipy: 2,2'-Bipyridine; COD: 1,5-Cyclooctadiene; DMF: $\mathrm{N}, \mathrm{N}$-dimethylformamide; FTIR: Fourier-transformed infrared spectroscopy; BINOL: 1,1'-Bi-2-naphthol; EXAFS: Extended x-ray absorption fine structure spectroscopy; HERFD-XAS: High-energy resolution fluorescence detected XAS; HRMS: High resolution mass spectrometry; LCA: Linear combination analysis; NMR: Nuclear magnetic resonance spectroscopy; TMEDA: Tetramethylethylenediamine; UVNis: Ultraviolet/Visible spectroscopy; XANES: X-ray absorption near edge spectroscopy; XAS: X-ray absorption spectroscopy.

\section{Competing interests}

The authors declare that they have no competing interests.

\section{Authors' contributions}

GJS and BNN both carried out the literature research and the writing of the manuscript. All authors read and approved the final manuscript.

\section{Acknowledgements}

We thank the EPSRC Dial-a-Molecule Grand Challenge Network for the invitation. GJS thanks the EPSRC and AstraZeneca for a CASE studentship.

Received: 25 November 2014 Accepted: 8 May 2015

Published online: 18 June 2015

\section{References}

1. Bordiga S, Groppo E, Agostini G, van Bokhoven JA, Lamberti C. Reactivity of surface species in heterogeneous catalysts probed by in situ X-ray absorption techniques. Chem Rev. 2013;113:1736-850.

2. Rodriguez JA, Hanson JC, Chupas PJ. In-situ Characterization of Heterogeneous Catalysts. 1st ed. Hoboken, New Jersey: Wiley; 2013.

3. Garino C, Borfecchia E, Gobetto R, van Bokhoven JA, Lamberti C. Determination of the electronic and structural configuration of coordination compounds by synchrotron-radiation techniques. Coord Chem Rev. 2014:277-278:130-86.

4. Tromp M, van Strijdonck GPF, van Berkel SS, van den Hoogenband A, Feiters MC, de Bruin B, et al. Multitechnique approach to reveal the mechanism of copper(II)-catalyzed arylation reactions. Organometallics. 2010;29:3085-97.

5. Ertel TS, Bertagnolli H. EXAFS investigations of air and moisture sensitive liquid compounds: Development of an appropriate sample holder with variable sample thickness and temperature control. Nuclear Instruments and Methods in Physics Research Section B: Beam Interactions with Materials and Atoms. 1993;73:199-202.

6. Hashmi ASK, Lothschuetz C, Ackermann M, Doepp R, Anantharaman S, Marchetti B, et al. Gold catalysis: in situ EXAFS study of homogeneous oxidative esterification. Chem - Eur J. 2010;16:8012-9.

7. He C, Zhang G, Ke J, Zhang H, Miller JT, Kropf AJ, et al. Labile Cu(I) catalyst/ spectator $\mathrm{Cu}(\mathrm{II})$ species in copper-catalyzed $\mathrm{C}-\mathrm{C}$ coupling reaction: operando IR, in situ XANES/EXAFS evidence and kinetic investigations. J Am Chem Soc. 2012;135:488-93.

8. Nchari LN, Hembury GA, Beesley AM, Meehan DJ, Tsapatsaris N, Hudson M, et al. Continuous tubular flow reactor for XAFS studies of organometallic reactions: possibilities and limitations for studies of the Soai reaction. J Phys Conf Ser. 2009;190:012156.

9. Bauer M, Heusel G, Mangold S, Bertagnolli H. Spectroscopic set-up for simultaneous UV-vis/(Q)EXAFS in situ and in operando studies of homogeneous reactions under laboratory conditions. J Synchrotron Radiat. 2010;17:273-9.

10. Lee PA, Citrin PH, Eisenberger P, Kincaid BM. Extended x-ray absorption fine structure - its strengths and limitations as a structural tool. Rev Mod Phys. 1981;53:769-806.

11. Evans J. Tilden lecture: shining light on metal catalysts. Chem Soc Rev. 1997;26:11-9.

12. Nguyen BN, Adrio LA, Barreiro EM, Brazier JB, Haycock P, Hii KK, et al. Deconvolution of the mechanism of homogeneous gold-catalyzed reactions. Organometallics. 2012;31:2395-402.

13. Hamilton GL, Kang EJ, Mba M, Toste FD. A powerful chiral counterion strategy for asymmetric transition metal catalysis. Science. 2007;317:496-9.
14. LaLonde RL, Wang ZJ, Mba M, Lackner AD, Toste FD. Gold(I)-Catalyzed Enantioselective Synthesis of Pyrazolidines, Isoxazolidines, and Tetrahydrooxazines. Angew Chem Int Ed. 2010;49:598-601.

15. Aikawa K, Kojima M, Mikami K. Synergistic effect: hydroalkoxylation of allenes through combination of enantiopure BIPHEP-gold complexes and chiral anions. Adv Synth Catal. 2010;352:3131-5.

16. Straub BF. Gold(i) or gold(iii) as active species in AuCl3-catalyzed cyclization/ cycloaddition reactions? A DFT study. Chem Commun. 2004: 1726-1728.

17. Schoch R, Desens W, Werner T, Bauer M. X-ray spectroscopic verification of the active species in iron-catalyzed cross-coupling reactions. Chem An Eur J. 2013;19:15816-21.

18. Bayram E, Linehan JC, Fulton JL, Roberts JAS, Szymczak NK, Smurthwaite TD, et al. Is it homogeneous or heterogeneous catalysis derived from $\left[\mathrm{RhCp}{ }^{*} \mathrm{Cl} 2\right] 2$ ? in operando XAFS, kinetic, and crucial kinetic poisoning evidence for subnanometer Rh4 cluster-based benzene hydrogenation catalysis. J Am Chem Soc. 2011;133:18889-902.

19. Widegren JA, Finke RG. A review of the problem of distinguishing true homogeneous catalysis from soluble or other metal-particle heterogeneous catalysis under reducing conditions. J Mol Catal A Chem. 2003;198:317-41.

20. Ellis PJ, Fairlamb IJS, Hackett SFJ, Wilson K, Lee AF. Evidence for the surfacecatalyzed Suzuki-Miyaura reaction over palladium nanoparticles: an operando XAS study. Angew Chem. 2010;122:1864-8.

21. Asakura H, Shishido T, Tanaka T. In situ time-resolved XAFS study of the reaction mechanism of bromobenzene homocoupling mediated by [Ni(cod)(bpy)]. J Phys Chem A. 2012;116:4029-34.

22. Glatzel P, Sikora M, Smolentsev G, Fernández-García M. Hard X-ray photon-in photon-out spectroscopy. Catal Today. 2009;145:294-9.

23. Safonova OV, Tromp M, van Bokhoven JA, de Groot FMF, Evans J, Glatzel P. Identification of $\mathrm{CO}$ adsorption sites in supported Pt catalysts using high-energy-resolution fluorescence detection X-ray spectroscopy. J Phys Chem B. 2006;110:16162-4.

24. Hämäläinen $K$, Siddons DP, Hastings JB, Berman LE. Elimination of the inner-shell lifetime broadening in X-ray absorption spectroscopy. Phys Rev Lett. 1991;67:2850-3.

25. de Groot F. High-resolution X-ray emission and X-ray absorption spectroscopy. Chem Rev. 2001;101:1779-808.

26. Glatzel P, Bergmann U. High resolution 1s core hole X-ray spectroscopy in $3 \mathrm{~d}$ transition metal complexes-electronic and structural information. Coord Chem Rev. 2005;249:65-95.

27. Bauer M, Gastl C. X-Ray absorption in homogeneous catalysis research: the iron-catalyzed Michael addition reaction by XAS, RIXS and multidimensional spectroscopy. Phys Chem Chem Phys. 2010;12:5575-84.

28. Bauer M, Kauf T, Christoffers J, Bertagnolli H. Investigations into the metal species of the homogeneous iron(III) catalyzed Michael addition reactions. Phys Chem Chem Phys. 2005;7:2664-70.

29. Guilera G, Newton MA, Polli C, Pascarelli S, Guino M, Hii KK, Hii KK. In situ investigation of the oxidative addition in homogeneous $\mathrm{Pd}$ catalysts by synchronised time resolved UV-vis/EXAFS. Chem Commun. 2006:4306-4308.

30. Bartlett SA, Wells PP, Nachtegaal M, Dent AJ, Cibin G, Reid G, et al. Insights in the mechanism of selective olefin oligomerization catalysis using stopped-flow freeze-quench techniques: A Mo K-edge QEXAFS study. J Catal. 2011;284:247-58.

\section{Publish with ChemistryCentral and every scientist can read your work free of charge \\ "Open access provides opportunities to our colleagues in other parts of the globe, by allowing anyone to view the content free of charge." W. Jeffery Hurst, The Hershey Company.}

- available free of charge to the entire scientific community

- peer reviewed and published immediately upon acceptance

- cited in PubMed and archived on PubMed Central

- yours - you keep the copyright

Submit your manuscript here:

http://www.chemistrycentral.com/manuscript/ Chemistry Central 